\title{
pÿYoung children s imaginative play and dynamic literacy practices in the digital age
}

\section{Sintonen, Sara}

Emerald

2018-11

pÿSintonen , S , Kumpulainen , K \& Vartiainen , J 2018 , Young children s imaginative play and dynamic literacy practices in the digital age . in G Oakley (ed.), Mobile Technologies in Children's Language and Literacy : Innovative Pedagogy in Preschool and Primary Education . Emerald, Bingley, UK, pp. 15-28 . https://doi.org/10.1108/978-1-78714-879-620181002

http://hdl.handle.net/10138/310676

https://doi.org/10.1108/978-1-78714-879-620181002

acceptedVersion

Downloaded from Helda, University of Helsinki institutional repository.

This is an electronic reprint of the original article.

This reprint may differ from the original in pagination and typographic detail.

Please cite the original version. 
Young Children's Imaginative Play and Dynamic Literacy Practices in the Digital Age

Sara Sintonen, Kristiina Kumpulainen and Jenni Vartiainen

\begin{abstract}
15 This chapter discusses children's imaginative play and literacy practices as mediated by mobile digital technologies and media. In this chapter, draw-

17 ing on sociocultural theory and the notion of dynamic literacies, we con-

19 sider how digital technologies including mobile technologies interact and potentially expand children's imaginative play, leading to dynamic literacy practices and learning opportunities. Based on this understanding, we will propose some pedagogical principles that can be applied to play-based early childhood education in support of young children's creative thinking, storytelling and dynamic literacy practices, both indoors and outdoors.
\end{abstract}

Keywords: Imaginative play; mobile digital technologies and media; creative thinking; dynamic literacies

\title{
1.1. Introduction
}

Eeli is a seven-year-old Finnish boy who, like many other children today, enjoys playing with Lego. Eeli's favourite Lego series is Ninjago. His reason for liking Ninjago so much is strengthened by a children's TV programme about Ninjago, which Eeli watches every week. He has many Lego Ninjago building blocks at home, and he builds constructions according to both available instructions and his own imagination. In addition to watching the TV series and playing with Lego blocks, Eeli engages in imaginative play marked by remarkable bodily expressions. His imaginative play does not include any objects but rather many

Mobile Technologies in Children's Language and Literacy: Innovative Pedagogy in Preschool and Primary Education, 15-28

Copyright $(\mathcal{C} 2018$ by Emerald Publishing Limited 
1 Ninja-like moves, battle sounds, running and jumping. At times, Eeli stops his imaginative play and retrieves his tablet device. He opens the online Lego

3 Ninjago catalogue and scans over it. He uses the catalogue to inspire his imaginative play. After a few minutes, he returns to his own imaginative play mode and continues acting out a world of play that is invisible to other people.

Eeli's Ninjago play is one example of a contemporary type of play characterised by dynamic literacy practices and seamlessly combining traditional and ascetic (solitary) imaginative play with digital resources (see also Marsh, Plowman, Yamada-Rice, Bishop, \& Scott, 2016; Potter \& McDougall, 2017). Agile shifts in the child's imaginative play between TV, Lego blocks and pictorial content enable him to engage in several important literacy practices. These include acting as the recipient and meaning-maker (TV), the producer (Lego building), the creator (imaginative play) and the developer (imaginative play enriched with tablet content).

In this chapter, we consider how digitally enriched imaginative play and the roles and positions children take in their play activity can nurture their literacy learning in dynamic and holistic ways. By dynamic literacies, we refer to hybrid literacy practices in which various tools and practices meet and intersect (see Potter \& McDougall, 2017). The chapter considers how pedagogy in children's

21 early years can purposefully harness their imaginative play via digital technologies and media to promote their literacy practices and early education. In the

23 approach advocated by our work, children's imaginative play is not separated from their use of digital technologies and media (see also Fleer, 2011), but is

25 instead seen as a natural part of the cultural toolkit children can use to create, build and make meaning of the world and of themselves. Hence, the chapter

27 argues against consumer-focused positioning of young children with digital technologies and media (see also Selwyn, 2003; Sorin, 2005, pp. 13-18), and pro-

29 poses that children should be viewed as active agents in using digital technologies and media in their imaginative play as a form of dynamic literacy

31 practices.

\subsection{Imaginative Play}

Researchers have long identified imaginative play as a vital component in the normal development of a child (Bergen, 2002; Garvey, 1993; Vygotsky, 1976). Imagination differs from normal reality, the material environment and the social presence of others and, as such, can widen our experience of the world (Zittoun \& Cerchia, 2013). Imagining creates a new space or form of thinking

41 with which children can surpass their own level of understanding and create a zone of proximal development for themselves (Vygotsky, 1962). Zittoun and

43 Gillespie (2016, p. 2) define imagination as 'the process of creating experiences that escape the immediate setting, which allow exploring the past or future, present possibilities or even impossibilities'. Imagination feeds on a wide range of experiences people have with or through the cultural world, through diverse 
1 senses, combined, organised and integrated in new forms (Zittoun \& Gillespie, 2016).

3 Similarly, Russ (2004, p. 141) noted that imaginative play helps children solve problems, especially in a creative fashion, and can assist children in reducing

5 anxiety and fear. He argued that when we leave some space for imagination, it is easier to cope with the constant flux of the world. For Brown (2010), imagina-

7 tion allows individuals to create 'simulated realities that [they] can explore without giving up access to the real world' (p. 86). Also, Egan (1997) highlighted the

9 importance of imagination for human development more generally, suggesting that imagining enables children to think beyond actuality to potentialities. $\mathrm{He}$

11 regarded imagination as the originator of invention, the novel and the flexible, while also underlining its role in rational thought. Overall, imagination is a fas-

13 cinating phenomenon. It is more embodied than we often give it credit for. For example, imagination can be used in rehabilitation from strokes: imagining

15 movement activates the same brain areas as actually physically moving (e.g. Mulder, 2007).

17 Walker and Gopnik (2013) suggested an interesting purpose for children's imaginative play: to provide children with the opportunity to practise the

19 cognitive skills necessary for causal cognition or the ability to think about cause-effect relationships. As they stated: "Pretend play and counterfactual

21 reasoning involve the same cognitive machinery: The ability to consider unreal events, to separate representations of those events from reality, and to

23 think about the outcomes of those events as if they had occurred" (Walker \& Gopnik, 2013, p. 43).

25 Play can be portrayed as a learning instrument with which children can practise developing skills.

27 Despite arguments that the digital age is depriving children of opportunities for imaginative play (Bodrova \& Leong, 2010; Karpov, 2005; Singer \& Singer,

29 2005; Smirnova, 2011), current research has provided evidence of children's agency in their play and interactions with digital technologies and media. In

31 fact, existing research has demonstrated dynamic literacy practices in children's digitally enriched play activities, whereby children seemingly weave together and

33 merge online and offline play (Marsh, 2010; Plowman, McPake, \& Stephen, 2010, 2012). For instance, in her study of the play preferences of Australian chil-

35 dren aged 20 months to five years, Edwards (2013) revealed how parents described their children's active remixing of play activities, in which more tradi-

37 tional roles and pretend play using dolls and teddy bears actively interacted with narratives associated with experiences gained from technology use involving

39 watching popular programmes on television, DVDs or online.

With respect to this association, Potter and McDougall (2017) introduced the

41 notion of the 'third space' (see also Bhabha, 1994), which they defined as a dynamic literacy space in which diverse meanings and learnings are negotiated

43 through the agentive activity of individuals - be they children or adults - in interaction with the social and material environment. In this chapter, we are 45 interested in how such third spaces are created in children's engagement in creative play in which more traditional play is remixed with their experiences of and 
1 with digital content, tools and media. We see great educational potential in such hybrid spaces for children's dynamic literacy practices and literacy learning.

\subsection{Imaginative Play, Dynamic Literacies and Literacy Learning}

Imaginative play is also known to form a basis for children's literacy development. For instance, children can practise language through pretend play with others; they can use their toys more symbolically, creating narratives and making rules and roles they can act out (White, 2012). Listening, reading, enacting and playing stories foster imagination as well. Stories inspire, evoke emotions and help children to retain information (Lawrence \& Paige, 2016). Storytelling involves connection and sharing. In a live situation, stories are created in the presence of recipients. Storytelling is a social activity as well as a communal process; the listener's role is as important as the narrator's. From a cultural perspective, stories are central to many cultures, as 'storytelling provides a platform and medium for retaining information that needs and should be retained' (Pattakos, 2011). Similarly, storytelling is important for children growing up in a culture insofar as it maintains a cultural continuum. As Brown (2009, p. 67) claimed, storytelling 'occupies a central place in early development and learning about the world, oneself, and one's place in it'.

According to Brown's (2009) typology of play, narrative play, of which storytelling is a prime example, encourages people to 'make up stories about why things are the way they are, which becomes our understanding of the world. Stories are a way of putting disparate pieces of information into a unified context" (p. 92). Similarly, Palmer (1996) described talking as playing because storytelling constitutes one form of children's play: "Language is the play of

29 verbal symbols that are based in imagery. Imagery is what we see in our mind's eye, but it is also the taste of a mango, the feel of walking in a tropical downpour, the music of Mississippi Masala. Our imaginations dwell on experiences obtained through all the sensory modes, and then we talk" (p. 3).

33 In Brown's (2009) typology, narrative play has much in common with imaginative play (creating simulated realities, immersion in imaginary worlds and events, moving freely back and forth between reality and fiction) and creative play - the transformation towards the unknown. Moreover, social play, which

37 comprises playing and sharing with others, overlaps with narrative, imaginative and creative play.

39 Contextualising play and storytelling in early childhood education is not a novel approach. Over 25 years ago, Paley (1990) wrote about play and storytell-

41 ing as the primary realities in preschool and kindergarten. Likewise, for Hendy and Toon (2001), play emerges from a shared creative activity in which stories

43 and tales are entwined with the play environments built according to children's ideas and wishes. Overall, children's imaginative play and dynamic literacy prac45 tices can be viewed as social practices in the literacy cultures created for and by the children. Participation in such cultures, including acting, playing and 
1 learning together, mediate and develop both children's and adults' interest in new phenomena, skills and knowledge, creating new forms of interaction and establishing new relationships.

Contextualising play, storytelling and literacy development in the digital era

5 have been a challenge for researchers. Extant research has problematised digital technologies as either negatively impacting the quality of children's play

7 (Singer \& Singer, 2005) or threatening children's imaginative capacity to play (Smirnova, 2011). More research is needed to understand the full potential of

9 children's imaginative play, volitional storytelling and digital production (Edwards, 2013; Marsh, 2010). As Bird and Edwards (2014) reported, rather

11 than being concerned over young children's use of technology in early childhood education settings, researchers should re-approach digital devices as catalysing a

13 change in children's innovative and symbolic activities. According to Bird and Edwards (2015), such devices are associated with promoting children's social

15 interactions, fostering thinking and laying the foundations for literacy learning - in other words, dynamic literacy. Another project, from Hill (2005),

17 revealed that the traditional content of reading and writing needs to be broadened to include the use of multiple sign systems that represent meaning. Young

19 children have always used constructions, drawings or illustrations, movements and sounds to represent meaning. In this respect, newer technologies merely add

21 to children's choice of mediums with which to represent ideas and comprehend meanings in a range of texts.

23 Research also suggests that providing a playful context wherein children can freely and agentively create and replay their story elements instead of following

25 adult-led activities leads to more structured and creative stories (Whitebread \& Jameson, 2010). The future of reading and writing is closely tied to the future

27 of digital technologies. Children already gain substantial experience with digital, multimodal texts at home. If we ignore new technologies and prevent young

29 children from accessing them, we risk disconnecting them from the world in which they live, as Yelland (1999), among others, mentioned almost two 31 decades ago.

Supporting young children's imaginative play and literacy practices with digi-

33 tal technologies can be considered a playful, embodied and creative action among young learners. It is important to combine play, imagination, creativity

35 and embodiment with digital learning in early childhood education (Sintonen, Ohls, Kumpulainen, \& Lipponen,2015). The advantage of mobile devices is that

37 they can be easily used when needed. In addition, mobile devices can be adapted to activities, bearing in mind that the activities are not dependent on these

39 devices. This requires careful and innovative pedagogical design: the learning activities of young children should not be limited to digital devices and other

41 new technologies and media, but should be augmented and supported through them, according to pedagogical guidelines.

43 For example, a smartphone can be taken along on a nature excursion and used to identify the names of flora and fauna that children find interesting; 45 photographs can also be taken depending on the moment and interests of the children. Photography is one of the basic functions of mobile learning that 
1 young children can use. Children can practise using cameras and recording their observations. For children, recording observations in more diverse ways than

3 only by verbal expression makes it possible to return to the experiences more effectively. Pictures and videos, for instance, trigger children's memory and help

5 them to process experiences further. From the adult point of view, offering children with versatile documentation tools and memory stimulants for storytelling,

7 would enable adults to better comprehend matters of significance to children worth recording.

\subsection{Towards a Pedagogy of Dynamic Literacies in Early Childhood Education}

13 The pedagogical principles advocated by our recent development efforts in

Finland to promote young children's dynamic literacies are multisensory, playful and story-like, and they encourage children to use their imagination, be creative and collaborate with each other (Kumpulainen, 2017; see also the work of Jacobs, 2013 and Leander \& Boldt,2013). These principles entail rich textual environments where the culture produced by children and the culture produced for them, such as fairy tales and stories, rhymes and poetry, music, TV programmes and films, digital games and applications, come into dialogue. Creating a rich, multimodal textual environment is aimed at inviting children to investigate, interpret, use and produce texts for various purposes and audiences. Learning environments are designed to generate flexible, pedagogically coherent and continuous entities (themes, phenomena) across the curriculum, drawing on children's social ecologies, including home cultures and literacies. The learning environments for multiliteracy learning can be situated in outdoor and indoor spaces, nearby nature areas, parks and cities, as well as in cultural institutions and digital and virtual spaces. Shifts in different learning environments and contexts are considered important in learning multiliteracies, and therefore, children's free time and home cultures cannot be overlooked.

As multiliteracy also includes media and digital literacies, a range of texts are introduced in digital modes and environments. Children are familiarised with various digital tools, media, applications and games in meaningful, playful and creative ways, and attention is paid to the significance and safe use of these tools in their everyday lives. Digital technologies and media are utilised to produce a

37 wide range of content and meaning. Digital documentation also plays an important role as an element of meaning making, experimentation, production and

39 knowledge exchange across children's social ecologies, such as at home and school (see Potter \& McDougall, 2017).

41 Early years pedagogy addressing dynamic literacies can depend on children's play, creative thinking and storytelling. This approach integrates digital technol-

43 ogies intrinsically and naturally in children's everyday activities. Teachers are encouraged to use a variety of interactions with texts, including digital texts, and 45 to choose the most suitable texts for various learning goals, especially those encompassing dynamic literacy practices. Children are encouraged to express 
1 themselves in multisensory, playful ways by using digital technology and creating their own content. When the concept of literacy is more widely considered

3 from the point of view of children's imaginative play and dynamic literacy, and digital tools and mobile devices become a more integral part of education

5 (including early childhood education), a collaborative, inclusive and multimodal environments reflecting contemporary digital culture can be created, as described 7 in the points below.

9 (1) The co-production of content, creativity, sharing, peer learning, advising and helping others and immediate feedback are activities that are character-

11 istic of, and familiar to, participants in digital cultures. Such activities could also serve as the basis for learning dynamic literacy practices in early child-

13 hood education.

(2) The use of a multitude of different forms of expression and tools can make both producing and receiving content more intriguing and meaningful to children. Multimodality challenges the traditional 'monomodal' pedagogy and materials in a positive way.

(3) Several methods exist for documenting and storing children's play interactions and their use and creation of artefacts. These can be used to indicate learning and improvement, to strengthen the feeling of ownership, for storytelling, as support material and to help in archiving memories.

(4) Not everything needs to be completed at once and by oneself; content can evolve, take different shapes and adjust to various situations, needs and participants. Adaptability and remixing are key for digital content creation.

(5) Digitisation has enabled visits to, and perusals of places, worlds and possibilities that are analogically inaccessible. This cultivates imagination and can form a basis for storytelling.

29 In sum, mobile technologies can be used to stimulate children's own creative production in a variety of ways. For instance, mobile devices such as tablets and smartphones can be used to make, record and share personal observations, thoughts, views and stories. In early childhood education, creative production can refer to, for example, digital stories, photos and photo collages, books (fairy tale books, nonfiction books and diaries), movies and other videos, music or games, made alone or collaboratively (Sintonen et al., 2015).

\subsection{Dynamic Literacies Approach in Early Years Pedagogy: An Example}

The following is an example of our development work regarding pedagogies and

43 learning materials for early years education, drawing on children's imagination, imaginative play, storytelling and dynamic literacies and enriched by digital technologies and media. Whisper of the Spirit is a set of activity cards with the educational aim of encouraging children to exercise their imagination and take 
1 an interest in Finnish nature and ancient myths from a variety of perspectives and modalities. The activity card tasks encourage children to imagine, observe,

3 collaborate, reflect, innovate and experiment in many ways, both indoors and outdoors (see Figure 1.1).

5 Nature has always been especially important to Finnish people, as the country's four seasons make for a rich and varied environment. It is thus unsurprising that the natural climate and geography of Finland has long kindled the imagination of the Finnish people and served as the source of many beliefs. For example, shooting stars were once believed to be cracks in the sky through which the Gods could peer down at the Earth. Similarly, forests and their spirit denizens were an essential part of the culture and way of life of Northern Finland, as forests were a critical food source.

Myths are culturally shared stories and beliefs about entities, events and places no one has seen or experienced but which are nonetheless held to be true. In the ancient past, Finnish myths often had their origins in observations of nature. The natural world inspired and fostered interaction by the Finnish people, who experienced a completely different relationship to nature than their modern descendants. As Lawrence and Paige (2016, p. 66) noted, myths possess a unique form of storytelling significance and value:

The elements of a great story are imagination, believability and content. In terms of the content, it is all about the problem, resolution and moral of the story. Moreover, a well-told story of the distant past can illustrate the value and importance of the myths we invent and how they serve to hold cultures together and empower individuals to build their lives around these experiences. (Lawrence \& Paige, 2016, p. 66)

The pedagogical material, Whisper of the Spirit, is currently widely used in Finnish early childhood education settings. The activities teachers have voluntarily developed around the material connect hands-on activities to digital production, documentation and remixing. For example, in one case, a teacher motivated preschool children (aged 5-6) with an image she had produced by using a mobile app called ChatterPix by Duck Duck Moose. She took a photo of a rock, drew a line to make a mouth and recorded the question, 'Would you like to hear my story?' with a lowered voice. She downloaded the talking image to ThingLink (www.thinglink.com), on which she had already uploaded one page from Whisper of the Spirit as a background image. After showing the materials to the group, the teacher asked the children whether they wanted to visit 41 the rock in a forest nearby and create their own stories. The children used their own documentation (digital photos, videos taken during the trip using mobile devices) and experiences (sensory experiences and observations in the woods and samples collected from nature), as well as their own imagination (individual and shared storytelling and voice-recorded narration) to create digital stories through, for example, an application called BookCreator by Red Jumper Ltd. 




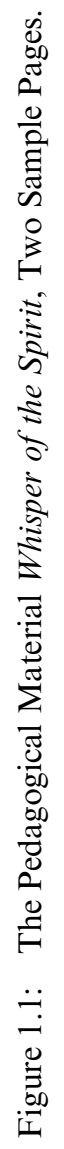

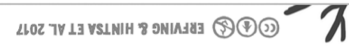

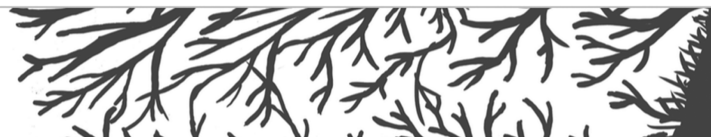


1 The children were allowed to use the media of their choice. Finally, all the material was gathered on the same ThingLink page the teacher had originally cre-

3 ated. After a week of working with Whisper of the Spirit, the children asked to look at the ThingLink page several times, and they also wanted to re-visit the

5 rock in the forest on several more occasions. This helped the children to develop their dynamic literacies by exploring and learning about the natural

7 world around them, albeit in different ways, through imagination and make-believe.

9 If ready-made content, such as various materials, images and stories are utilised in mobile literacy learning, they must be pedagogically appropriate and of

11 high quality. They must also both interest children and support their learning. Manufacturers of such products should also be cognisant of the impact they

13 have on children; from the perspective of early childhood education, it is vital that the content produced for children is high quality, ethically and aesthetically

15 sustainable and suitable for use on mobile devices. It should also leave enough space for children's own thoughts.

\subsection{Closing Thoughts}

Imagination and storytelling are an essential part of children's play activities and should be included in literacy and learning practices in formal early childhood education. Open-ended activities, such as creative play, instead of prescrip-

25 tive activities, foster diverse thinking among children. Digital devices and media should not be regarded as antithetical to creative play and learning but rather as an integral part of children's dynamic literacies in the twenty-first century. As Paley (1990) noted some time ago, storytelling is the primary reality in preschool and kindergarten. The same reality still exists nowadays. However, contemporary storytelling is rooted in much richer communication than verbal expression alone.

As our examples of Eeli's Ninjago play and Whisper of the Spirits how, contemporary digital devices can expand children's imaginative play and storytelling, positioning children within hybrid literacy practices that entail acting as the recipient and meaning-maker (TV), the producer (Lego building), the creator (imaginative play) and the developer (imaginative play enriched with tablet content). Moreover, new technologies provide a wide variety of possibilities for children to share and document the processes and products of their imaginative play, in turn broadening their audiences. For example, pictures and videos of Lego creations can be uploaded in an application, and then shared with and reviewed by other Lego builders. These new extensions, mediated by digital technologies and media, demonstrate a kind of 'third-space': a hybrid space in which several meanings and learnings are shared, negotiated and represented through the agentive activity of children in interaction with the social and material environment. 
1 Below, we summarise some practical advice and pedagogical principles to promote young children's imaginative play and dynamic literacy practices in

3 early childhood education, using digital technologies including mobile devices:

5 - Let children try out different digital tools and technologies at a very young age in various contexts. Carry such tools with you as a part of your ordinary,

7 day-to-day life and take inspiration from the situations, moments and places where you use them.

9 - Inspire and encourage children to create their own content, to be creative with digital devices. Relate imaginative and creative play to digital production.

11 Learn to recognise what constitutes natural and positive creative moments from the children's viewpoint.

13 - Use a various range of modalities (e.g. visual, aural, etc.) in content production and create diverse texts - for example, images and soundtracks - con-

15 taining the same information.

- Supply a wide range of digital devices and content when possible, as being

17 restricted to one tool or type of content also restricts what can be accomplished. There is no need to buy everything: you can also borrow, exchange or

19 share. Let your children know about your media history and the devices you have used in the past.

21 - Learn about different digital technologies, tools and various applications together with colleagues, children and parents. Many great features of devices

23 and production environments often go unused when adults have not acquainted themselves with them. Allow the children to take the role of an

25 expert now and then.

- Show interest and take part in the digital worlds of children as well as their

27 creative experiments and offer them diverse opportunities for creative play and learning. Discuss with children the content they have created, ask them

29 questions and share your remarks.

- It is a good idea to take part in child-led activities that make use of mobile 31 devices. Show your interest and be excited by the content they are producing. Also, try out new things for yourself and let children give you instructions.

- When you comment or give feedback to children, always have something positive to say and explain your views. Consider what you see and experience in

35 their productions, and discuss with them how different audiences might respond to these productions.

37 - Encourage sustained play and resilience in children's creative productions and work. Remember that the actual process of creation is as meaningful and

39 important as the final product.

41 Being creative, playful and imaginative in early education is not always a pleasant experience for teachers but occasionally demanding, difficult and confronta-

43 tional. At the same time, it can be very rewarding. It raises - and should raise - questions about the fundamental structures of power, authority and

45 resistance in our society (see Sefton-Green et al., 2015). If imagination and creativity are conceptual tools with which children adapt to change and handle the 
1 unknown and unpredictable, why are children not given opportunity to dynamic literacy practices and tools for their bodily sense making and production of their world? Dynamic literacy of young children should not be limited by digital mobile devices but to be considered as a playful, embodied, creative and imaginative actions with and through them.

\section{References}

9 Bearne, E., \& Wolstencroft, H. (2007). Visual approaches to teaching writing Multimodal literacy 5-11. London: Paul Chapman Publishing.

Bergen, D. (2002). The role of pretend play in children's cognitive development. Early Childhood Research and Practice, 4, 1-12.

13 Bhabha. (1994). The location of culture. New York, NY: Routledge.

Bird, J., \& Edwards, S. (2015). Children learning to use technologies through play: A digital play framework. British Journal Education Technology, 46, 1149-1160. doi:10.1111/bjet.12191

Bittman, M., Rutherford, L., Brown, J., \& Unsworth, L. (2011). Digital natives? New and old media and children's outcomes. Australian Journal of Education, 55(22). Retrieved from http://research.acer.edu.au/aje/vol55/iss $2 / 6$

Bodrova, E., \& Leong, D. J. (2010). Curriculum and play in early child development. In R. E. Tremblay, R. G. Barr, R. De, V. Peters, \& M. Boivin, (Eds.), Encyclopedia on early childhood development [online] (pp. 1-6). Montreal, Quebec: Centre of Excellence for Early Childhood Development. Retrieved from http://www.child-encyclopedia.com/documents/Bodrova-LeongANGxp.pdf

Brown, S., \& Vaughan, C. (2009). Play: How it shapes the brain, opens the imagination, and invigorates the soul. New York, NY: Avery.

Edwards, S. (2013). Digital play in the early years: A contextual response to the problem of integrating technologies and play-based pedagogies in the early childhood curriculum. European Early Childhood Education Research Journal, 21(2), 199-212. doi:10.1080/1350293X.2013.789190

Egan, K. (1997). The educated mind: How cognitive tools shape our understanding (p. 299). Chicago, IL: University of Chicago Press.

Egan, K. (2006). Teaching literacy: Engaging the imagination of new readers and writers. Thousand Oaks, CA: Corwin Press.

Fleer, M. (2011). Technologically constructed childhoods: Moving beyond a reproductive to a productive and critical view of curriculum development. Australasian Journal of Early Childhood, 36(1), 16-25.

37 Garvey, C. (1993). Play. Cambridge, MA: Harvard University Press.

Hendy, L., \& Toon, L. (2001). Supporting drama and imaginative play in the early years. Buckingham, UK: Open University Press.

Hill, S. (2005). Mapping multiliteracies: Children in the new millennium. Report of the research project 2000-2004. Adelaide: University of South Australia. Retrieved from http://www.unisanet.unisa.edu.au/staff/suehill/mapping_multiliteracies.pdf

Jacobs, G. E. (2013). Reimagining multiliteracies: A response to Leander and Boldt. Journal of Adolescent \& Adult Literacy, 57(4), 270-273.

45 Karpov, Y. V. (2005). The neo-Vygotskian approach to child development. Cambridge: Cambridge University Press. 
1 Kumpulainen, K. (2017). Promoting multiliteracies from early years onwards: Insights to an ongoing educational reform effort in Finland. Manuscript submitted for publication.

Lawrence, R. L., \& Paige, D. S. (2016). What our ancestors knew: Teaching and learning through storytelling. New Directions for Adult and Continuing Education, 2016(149), 63-72.

Leander, K., \& Boldt, G. (2013). Rereading “a pedagogy of multiliteracies": Bodies, texts, and emergence. Journal of Literacy Research, 45(1), 22-46. doi:10.1177/ 1086296 X 12468587

Marsh, J. (2010). Young children's play in online virtual worlds. Journal of Early Childhood Research, 8, 23-39.

Marsh, J., Plowman, L., Yamada-Rice, D., Bishop, J., \& Scott, F. (2016). Digital play: A new classification. Early Years, 36(3), 242-253. doi:10.1080/09575146. 2016.1167675

Mulder, T. (2007). Motor imagery and action observation: Cognitive tools for rehabilitation. Journal of Neural Transmission, 114(10), 1265-1278. doi:10.1007/s00702 -007-0763-Z

Paley, V. G. (1990). The boy who would be a helicopter. Cambridge, MA: Harvard University Press.

Palmer, G. B. (1996). Toward a theory of cultural linguistics. (1st ed.). Austin, TX: The University of Texas Press.

Pattakos, A. (2011). Modern storytelling and the search for meaning. A blog. Retrieved from http://www.huffingtonpost.com/alex-pattakos/storytelling-culturemeaning_b_814798.html

Plowman, L., McPake, J., \& Stephen, C. (2010). The technologisation of childhood? Young children and technologies at home. Children and Society, 24(1), 63-74.

Plowman, L., McPake, J., \& Stephen, C. (2012). Extending opportunities for learning: The role of digital media in early education. In S. Suggate \& E. Reese (Eds.), Contemporary debates in child development and education. (pp. 95-104). London: Routledge.

Potter, J., \& McDougall, J. (2017). Digital media, culture and education. Theorising third space literacies. London: Palgrave Macmillan UK.

Russ, S. W. (2004). Play in child development and psychotherapy. New York, NY: Routledge.

Sefton-Green, J., Kumpulainen, K., Lipponen, L., Sintonen, S., Rajala, A., \& Hilppö, J. (2015). Playing with learning. Helsinki: University of Helsinki. Retrieved from https://helda.helsinki.fi/handle/10138/158664

Selwyn, N. (2003). 'Doing it for the kids': Re-examining children, computers and the 'information society'. Media, Culture \& Society, 25(3), 351-378.

Sicart, M. (2014). Play matters. Cambridge, MA: MIT Press.

Singer, D. G., \& Singer, J. L. (2005). Imagination and play in the electronic age. Cambridge, MA: Harvard University Press.

Sintonen, S., Ohls, O., Kumpulainen, K., \& Lipponen, L. (2015). Mobile learning and the playing child. University of Helsinki. Retrieved from https://helda.helsinki.fi/handle/10138/155512

45 Smirnova, E. (2011). Character toys as psychological tools. International Journal of Early Years Education, 19(1), 35-43. 
1 Sorin, R. (2005). Changing images of childhood:Reconceptualising early childhood practice. International Journal of Transitions in Childhood, 1(1), 12-21.

3 Vygotsky, L. S. (1962). Thought and language. Cambridge: MIT Press.

Vygotsky, L. S. (1976). Play and its role in the mental development of the child. In

5 J. Bruner, A. Jolly, \& K. Sylva (Eds.), Play: Its role in development and evolution (pp. 76-99). New York, NY: Basic Books.

7 Walker, C. M., \& Gopnik, A. (2013). Pretense and possibility: A theoretical proposal about the effects of pretend play on development: Comment on Lillard et al.

9 (2013). Psychological Bulletin, 139(1), 40-44.

White, R. (2012). The power of play: A research summary on play and learning.

11 St. Paul, MN: Minnesota Children's Museum.

Whitebread, D., \& Jameson, H. (2010). Play beyond the foundation stage: Storytelling,

13 creative writing and self-regulation in able 6-7 year olds. In J. Moyles (Ed.), The excellence of play. (3rd ed., pp. 95-107). Maidenhead, UK: Open University Press.

15 Yelland, N. (1999). Technology as play. Early Childhood Education Journal, 26(4), $217-220$.

Zittoun, T., \& Cerchia, F. (2013). Imagination as expansion of experience. Integrative Psychological and Behavioral Science, 47(3), 305-324. doi:10.1007/

19 s12124-013-9234-2

Zittoun, T., \& Gillespie, A. (2016). Imagination in human and cultural development. London: Routledge.

\section{Uncited References}

25 Bearne and Wolstencroft (2007); Bittman, Rutherford, Brown, and Unsworth (2011); Brown and Vaughan (2009); Egan (2006); Sicart (2014) 